\title{
Evaluation and benchmarking of lean manufacturing system environment: A graph theoretic approach
}

\author{
Rakesh Kumar* and Vikas Kumar
}

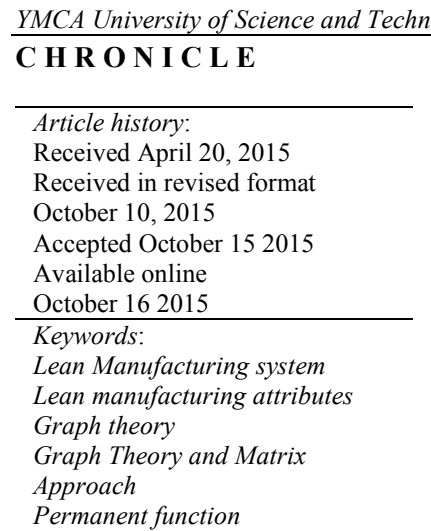

\begin{abstract}
A B S T R A C T
Manufacturing industries are consistently working on improving their operational performance to remain competitive in the market. LM is a well-recognized approach for improving the overall performance. It contains several elements covered under a few lean attributes. This paper presents the application of Graph Theory and Matrix Approach (GTMA) for the identification of relative importance of different lean attributes in a lean environment using qualitative and quantitative factors. The Lean Manufacturing Attributes (LMA's), affecting the overall LM environment, of a manufacturing industry were identified and analyzed for the implications on the managerial decisions. .In this proposed study, The GTMA approach is applied to prioritize the LMA's based on their relative importance.
\end{abstract}

(C) 2016 Growing Science Ltd. All rights reserved.

\section{Introduction}

Lean manufacturing (LM) was developed and practiced, for the first time, in Toyota Motors Japan to maximize value and minimize waste in the manufacturing system. Initially it was known as Toyota Production System or TPS but in late 90's it became famous as LM system after the book "The machine changed the world" written by Womack (Kumar \& Kumar, 2015). LM tools like kanban, kaizen, Andon and Heijunka are derived from Japanese language (Shah \& Ward, 2003). LM is used to refer a manufacturing approach synonym with working with lower inventories throughout the value stream for reducing cost and improving quality (Singh et al., 2009). Recognition of value is the core of Lean Manufacturing system (Taj \& Morosan, 2011). It may be defined as a characteristics or a feature of the product for which a customer is willing to pay for and everything else may be considered as waste. LM emphasizes on identification and elimination of all types of waste in the system (Kumar \& Kumar, 2014). This approach got popularity in industry because LM practicing companies were able to achieve better output with lesser resources like human effort, machines, material, floor space, capital investment and time as compared to non lean practicing companies (Womack et al., 1990). Therefore,

* Corresponding author

E-mail address: rakesh siwach@yahoo.com (R. Kumar)

(C) 2016 Growing Science Ltd. All rights reserved.

doi: $10.5267 /$ j.uscm.2015.10.003 
it is important for industries to accelerate the initiatives which are necessary for the Lean implementation. This requires the practitioners to know about the relative importance of LMA's in manufacturing environment which will direct them to take actions efficiently. This paper formulates a methodology using GTMA to evaluate the LMA's relevant to manufacturing industries.

\section{Literature review}

Initially LM was developed with the intention to work with lower inventories and removing all kind of wastes from manufacturing system by adopting more creative manufacturing methods and improving product quality (Chowdary \& George 2011). In fact, industries are always looking for innovative ways to get competitive edge over their competitors. Nowadays, increasing global competition has further increased the intensity of the search for innovative ways of cost reduction by eliminating non value adding activities to stay alive in the competitive world (Kumar V, 2010). LM is one of such system industries are looking for reducing product cost and increasing quality (Dombrowski et al., 2012). Indian industries are also looking for such innovative manufacturing methods to keep themselves competitive in their market segment (Ahuja \& Khamba, 2008). LM is the preferred approach to address the manufacturing issues and reduce waste. Indian industries have started adopting Lean, derived from extensive benefits gained by companies who have implemented LM and enhanced their manufacturing performance (Upadhyay et al., 2010).

In LM, the movement of material through the value stream is termed as "Flow". The flow is maintained unidirectional, continuous and free from obstacles like waiting, backflow and bottlenecks by continuously increasing value of activities in the manufacturing process. This is accomplished by a systematic approach to the identification and elimination all forms of waste from the value stream. The aim of LM is to make the product only when it is needed and the quantity what is demanded by customer (Mishra \& Garg, 2013). LM is a philosophy of manufacturing that focuses on delivering the highest quality product on time and at the lowest cost (Nordin et al., 2010). LM is reliant on continuous improvement process for long term maximization of company resources. In Lean manufacturing, production processes are connected such that the production is pulled by the downstream process and the upstream process will produce only what is requested by the next process.

The other important aspect of LM is defect free manufacturing processes. It aspires for elimination of defects at the source. The product quality inspection is supposed to be performed by the workers as part of the production process (Kumar \& Kumar, 2012). LM focuses for achieving operational perfection by continually removing wastes with a high level of worker involvement in the process improvement (Silva, 2012). Segregation of value adding and non value adding activities is the first step in lean manufacturing approach followed by eliminating non value adding activating to reduce the input cost (Pepper \& Spedding, 2010). Manufacturing companies are required to accommodate LM into their daily work practices for getting maximum benefits (Kumar \& Kumar, 2015). Although LM is preferred approach for reducing manufacturing costs by eliminating waste from manufacturing processes (Anand \& Kodali, 2008); still Indian industry has not gained full advantage due to its limited implementation (Khadse et al, 2013).

LM is illustrated from two viewpoints, one from a theoretical viewpoint associated to philosophical guidelines and second a practical viewpoint describing management tools techniques, practices, (Shah \& Ward, 2003; Li et al., 2005) and finally outcomes (Spear \& Bowen, 1999). LM has been described in the most of the articles as an effective system (Kumar \& Kumar, 2015) but the correlation between the lean structure and its elements has not been extensively discussed.

When data reduction method was carried out to collapse several LM elements into a lesser number, it was observed that several different elements of LM were used to measure the implementation of LM but functionally they are similar and overlapping each other creating confusion in the literature. This paper attempts to create a novel lean structure based on vital elements of lean manufacturing system 
described by Shah and Ward (2007). This paper also checks the individual importance of each lean element and attribute in the LM environment of the organization. These major elements of a LM system are considered as supplier feedback, JIT delivery by suppliers, supplier development, and customer's involvement, pull, continuous flow, set up time reduction, total productive, statistical process control and employee involvement. Employee's involvement is the main aspect of LM implementation to identify and reduce the waste from the manufacturing system to utilize the required resources in an effective manner (Shah \& Ward, 2003).

\section{LM environment}

In a stable LM environment lean tools are placed and practiced in a harmonic way and thus every step of manufacturing process is evaluated by defined values. LM directs individuals and the organizations to focus on the resources for adding the value. Product is manufactured against customer demand and pulled through value stream by down-stream process from up-stream processes and in this way the whole manufacturing processes are synchronized with the customer demand. Inventories between processes are reduced to a minimum level and low inventories in the system keep inventory carrying cost on lower side (Mishra et al., 2013). A known small amount of inventory of finished goods is kept and is replaced with fresh stock when the existing stock gets depleted and is unable to meet the customer demand. Application of setup time reduction makes manufacturing system more flexible and quick to respond for varying customer demands. An important practiced tool in lean environment is continuous improvement which requires involvement of employees. Identification of waste and its quick elimination offers instant gain.

Thus with the application of LM organizations are able to sustain competitiveness in the market thereby improving their competence with acceptable quality, timely delivery and lower cost. Different lean factors identified and validated by researchers are: JIT supplies, Supplier development, Supplier Feedback, Kanban, TPM, Lead time Reduction /Single piece flow, Cellular Layout /Layout improvement, Quality Circles/Quality at the Source, Kaizen, 5 S's, Employee's involvement/development, Continuous improvements, Standard Work, Visual Management, FIFO and Customer feedback LM environment in any organization is determined by level of implementation of these lean tools. The understanding about importance of each lean attribute is important and plays a vital role in lean manufacturing implementation.

Based on literature review and extensive discussions with professionals, all major LM elements were categorized into four main lean attributes. A configuration was developed to clarify how LM elements construct an attribute and how attributes contribute to lean LM implementation. Lean tools are practiced from supplier, through the manufacturing plants and to the final delivery to the customers covering all the stakeholders. The diagram in the Figure 1 explains the flow of lean practices in the manufacturing supply chain in the form of value stream. All lean elements were categorized into four Lean Attributes based on their domain of implementation as below:

1. Supplier oriented practices (Supplier Participation)

2. Manufacturing oriented practices (Operational initiatives)

3. Employees involvement in lean practices (Employees involvement)

4. Customer oriented practices (Customer Participation) 


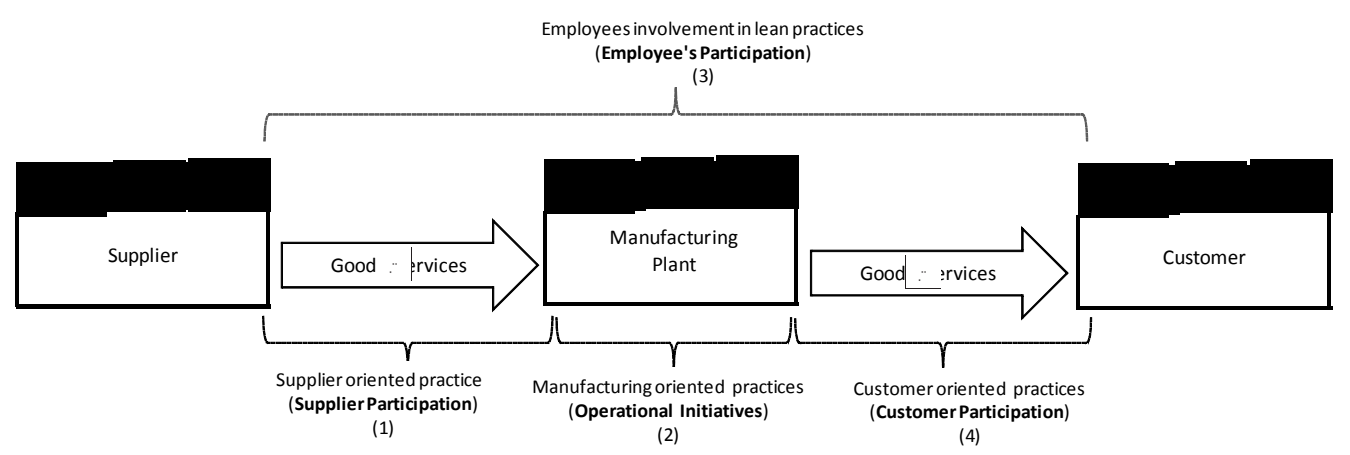

Fig. 1. Diagram showing application of Lean manufacturing practice in a value stream

\subsection{Supplier Participation}

The LM activities performed between supplier and buyer with the involvement of supplier is termed as supplier oriented practices or supplier participation in lean manufacturing. Lean manufacturing focuses on making processes simpler starting from interaction with supplier, in-house manufacturing and finally the customer. It promotes involvements of stakeholders within and beyond the boundaries of the manufacturing plant. To maintain the on time delivery status to customer, right quality and timely supplies from supplier is essential. Competent and limited numbers of suppliers can play vital role in robust supply chain development. Timely deliveries allows manufacturing organizations to keep inventories level low and reduces response time in procuring right quality and defect free parts from supplier. This shall improve the organizational performance. Supplier Participation lean tools include JIT supplies, Supplier development and Supplier rating. Sound relation based on better communication is essential between buyer and supplier to maintain uninterrupted supplies. Lesser work in process (WIP) inventory can be achieved through reduced batch sizes.

\subsection{Operational initiatives}

The LM practices performed within the manufacturing plant for improving operational efficiency are called manufacturing oriented lean practices or Operational initiative. It involves the lean tools practiced to improve the manufacturing operation of the organization. Operational initiatives involve lean tools as first in first out (FIFO), Quick changeovers, statically process control (SPC) techniques, work standardization, total productive maintenance (TPM) and Visual Management. Overall motive of operational initiatives is to maintain linear and unidirectional flow of material through the manufacturing lines. Reduced changeover time enables organizations to work with reduced inventories between work stations and improve manufacturing flexibility.

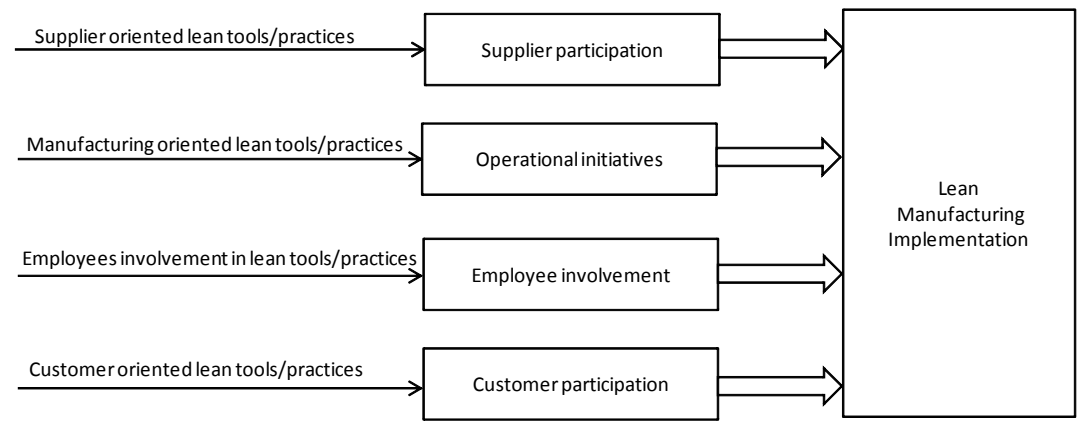

Fig. 2. Diagram showing participation of attributes in Lean manufacturing implementation

Statistical process control techniques reduce the variation in the product quality and improve uptime of the machines by reducing stoppage of lines for quality reasons. Standardized work is another vital lean element under operational initiatives used for standardizing the repeated activities so that each activity is performed in a specified way. This helps to enhance the operator's skill and variation by improving 
the inefficient practice adopted by the operator. Total productive maintenance is a lean element practiced to increase the reliability and availability of equipment to avoid unplanned breakdown. Visual management is a lean tool which enables to monitor the actual status against the standards like process parameters of equipment, status of manufacturing output, identification of bottlenecks and visual display for safety related points.

\subsection{Employee's involvement}

Lean practices having involvement of people is termed as employee's involvement in LM implementation. Employees are the critical assets of any organization and organizations enhance their knowledge levels \& hone their skills to have a competitive advantage over their competitors. Enhanced organizational performance is eventually based on the people in the organization so nowadays employees has been considered as human capital for an organization as compared to a cost factor in the past which was comprehended essential to be controlled or reduced. LM implementation requires higher intellectual work content over the traditional work so employees are now considered as a strategic resource. Though this resource covers the whole umbrella of LM still there are some specific lean tools and practices where organization needs extensive and continuous involvement of employees like People development, 5S, Kaizen and quality circles.

\subsection{Customer Participation}

The LM activities performed in participation with customer are termed as Customer oriented lean practices or customer participation in LM. LM concept itself is a customer-driven manufacturing. LM supports frequent and direct contact with customer for understanding on customer demand and establishes effective communication with customer. Customer Participation lean tools includes Kanban, online customer demand access and customer feedback. Customer is the driving the demand for the manufacturing system either it is push or pull type. Push system is termed as traditional manufacturing and pull system is termed as LM. Nevertheless, the major differentiation is in how customer demand is handled. Customer associated with LM uses Kanban for raising demand. Use of Kanban enables manufacturer to know the exact demand in terms of quantity and time thus resulting into control of wastage in the form of overproduction. Sometimes, customer uses e-Kanban for raising demand online. Feedback from customer is an essential element in terms of exploring the area of improvement

\section{Relative importance of Lean Attributes}

Within the LM attributes i.e. Supplier Participation, Operational initiatives, Employees involvement, Customer Participation it is imperative to understand individual contribution in LM implementation, their importance, impact on culture of the organization and its performance. Unsighted focus on specific LM attribute, overlooking any one or more attribute, may lead the organization away from expected result of LM implementation. There is specific importance and contribution of each of attribute in lean environment. Within the scope of this research paper, measure of importance of lean attributes to formulate understandable relationship with the LM environment index.

\section{Graph Theoretic and Matrix approach (GTMA)}

The Graph Theory application is centuries old approach used to resolve the complex problem with the help of diagraphs and matrices. Graph theory has been used in resolving various problems in the fields of economics, mathematics, communication, operations research science and technology (Gross \& Yellen, 2005; Biswal, 2012). Many complex issues has been discussed and resolved by researchers with the use of graph theory (Pemmaraju \& Skiena, 2003). In this paper the relative importance of various LM attributes is discussed in a lean manufacturing environment of an organisation. This may guide the companies to know about the focus area for lean manufacturing. 


\subsection{Methodology}

Graph theoretic approach is used to obtain a synthesized score for a complex system having many variables in the form of lean attributes and sub variables in the form of lean elements. In the given study graph theory application is used to interconnect between different lean attributes and elements. Diagraph for different lean attributes and lean elements is drawn considering their relative importance and directions. This approach has helped to develop a mathematical model for role of human factor TQM environment by Grover et al. (2006).Failure cause analysis of machine tools is assessed using digraph and matrix by Rao and Gandhi (2002). Similarly identification of an index for significance of different lean attributes in LM environment is proposed in this paper. The methodology adopted consists of following major steps:

1. Recognition of different lean attributes enabling implementation of LM.

2. Development LM environment diagraph taking lean attributes, their relative importance and interdependencies into account.

3. The diagraph consists of nodes equal to lean attributes showing their relative importance and corresponding directions.

4. Recognition of different lean elements for lean enablers.

5. Development of diagraph for element showing directions based on relative importance among each other.

6. Determine the permanent function value for lean attribute and element level. Numerical values are used for diagonal elements and inter-connections.

7. Develop a matrix with diagonal and off-diagonal elements. The permanent function value of each element is provided at diagonal elements for each attribute. The value of interaction among off diagonal is to be decided by the professionals as per Table no. 2 on the scale of 1-5.

8. Determine the permanent function of 'Matrix' at the lean attribute level. This value is a benchmark LM environment of any organization.

\subsection{Illustrative example}

The proposed technique is illustrated in a specific case of a manufacturing organisation" X". The Lean environment value is determined of this organization by assigning the quantified values of individual importance of lean attributes $\left(\mathrm{A}_{1} \ldots \mathrm{A}_{4}\right)$ and their relative importance (aij) in the matrix equation 1.To allocate quantified value for lean attributes $\left(\left(\mathrm{A}_{1}, \mathrm{~A}_{2}, \mathrm{~A}_{3}\right.\right.$ and $\left.\mathrm{A}_{4}\right)$ a survey was conducted in the manufacturing organization at all levels . Professionals from industries and academic were requested to assign the quantified value. Following steps were followed to apply graph theory in this organization.

Step 1: Identification of factors contributing to lean environment of the organisation. The four major factors identified in previous section are: Supplier participation, Operational initiatives, Employees participation and Customer participation.

Step 2: Graph theoretic model development for lean environment for the organization. Following substeps were taken for application of graph theory

i. Construction of Digraph

ii. Matrix representation and

iii. Computation of Permanent function for each matrix.

The following four major lean attributes were recognized in the previous section to take care of all ten lean elements identified by Shah and Ward (2003). The following four major attributes are considered as contributing factors for finding lean environment index.

A1: Supplier participation (SP)

A2: Operational initiatives (OI)
A3: Employees participation (EP)

A4: Customer participation (CP) 
Construction of the Digraph for LM environment

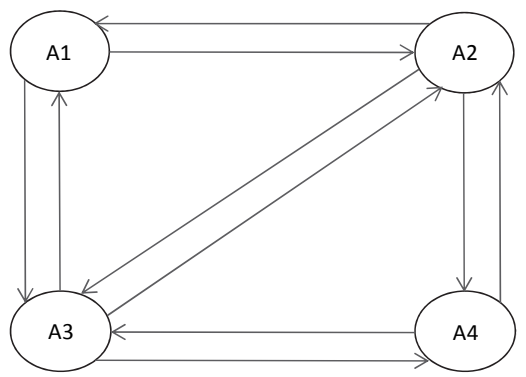

Fig. 3. Diagraph of LM attributes within lean environment

The matrix contains terms A1 A2 A3 and A4 which indicates LM attributes. The relative importance among the LM attributes is not yet represented by this characteristic function. Consequently it is essential to investigate the aspect of relative importance among different lean attributes digraph and its matrix. If the $\mathrm{i}$-th lean attribute is more important than the $\mathrm{j}$-th lean attribute, then direction of arrow is shown from $i$ to $j$ to represent this relative importance. If there is no comparison or direct link between lean attributes there is no direction is shown in the digraph.

Step 3: Recognition of attributes of each dimension. The lean element and attributes are acknowledged through literature review as discussed in previous section Table no. 1 is illustrating the allocation of lean attributes and elements.

\section{Table 1}

Distribution of LM tools into Lean Attributes

\begin{tabular}{cccl}
\hline S. No. & Lean Attributes & & Lean Elements \\
\hline 1 & Supplier participation & i & JIT supplies from supplier \\
& & ii & supplier development \\
\hline 2 & Operational initiatives & iii & Supplier rating \\
\hline & & i & FIFO \\
& & ii & SMED \\
& & iii & SPC \\
& iv & Standard Work \\
\hline 3 & Employee involvement & v & TPM \\
& & vi & Visual Management \\
& & i & 5 S \\
& ii & Continuous improvements \\
& & iii & Lead time reduction \\
\hline 4 & Customer participation & iv & Kaizen \\
& & v & Quality circles \\
\hline & & i & Customer feed back \\
& & ii & Kanban \\
\hline
\end{tabular}

\subsection{Matrix representation of the matrix representation of the digraph}

\begin{tabular}{|c|c|c|c|c|}
\hline & SP & Ol & EP & $\mathrm{CP}$ \\
\hline $\mathrm{SP}$ & $\mathrm{A}_{1}$ & $a_{12}$ & $a_{13}$ & $a_{14}$ \\
\hline OI & $a_{21}$ & $\mathrm{~A}_{2}$ & $a_{23}$ & $a_{24}$ \\
\hline EP & $a_{31}$ & $a_{32}$ & $\mathrm{~A}_{3}$ & $a_{34}$ \\
\hline $\mathrm{CP}$ & $a_{41}$ & $a_{42}$ & $a_{43}$ & $\mathrm{~A}_{4}$ \\
\hline
\end{tabular}


The importance index is assumed on Likert scale from 1 to 5,1 is assumed for very low importance whereas 5 for very high importance of the lean attributes as shown in table below.

Table 2

Quantification of relative importance for off- diagonal elements

\begin{tabular}{clc}
\hline S. No. & Quantitative scale to measure relative importance of Lean attributes & Value assigned based relative importance \\
\hline 1 & Very high & 5 \\
2 & Strong & 4 \\
3 & Medium & 3 \\
4 & Weak & 2 \\
5 & Very low & 1 \\
\hline
\end{tabular}

Since there are no relative importance loops in the corresponding lean attributes digraph, in such case, $\mathrm{a}_{\mathrm{ij}}\left(\right.$ or $\mathrm{a}_{\mathrm{ji}}$ ) is assigned zero value in the matrix representation of the digraph.

All the major lean attributes responsible for the lean environment of industry and their relative importance have been considered in the below matrix. The characteristic function i.e. the determinant of the characteristic matrix contains signs, negative and positive and hence may not be able to solve the entire purpose since some of the information is lost in the calculation process of the determinant function. Because of this reason, we have used the permanent function of a matrix, which does contains positive signs and no negative sign, and thus presents the full information of the system. A method for the assessment of relative importance of lean attributes in a lean environment of an organization is presented. Lean environment index for lean attributes can be defined as the individual importance of a particular lean attributes over the others in a LM environment.

\begin{tabular}{|c|c|c|c|c|}
\hline & SP & OI & EP & $\mathrm{CP}$ \\
\hline SP & $\mathrm{A}_{1}$ & 2 & 2 & 0 \\
\hline OI & 4 & $A_{2}$ & 5 & 4 \\
\hline EP & 3 & 5 & $\mathrm{~A}_{3}$ & 3 \\
\hline$C P$ & 0 & 3 & 2 & $\mathrm{~A}_{4}$ \\
\hline
\end{tabular}

Lean environment index $(\mathrm{Li})=\operatorname{Per}\left(\mathrm{F}^{*}\right)=$ Permanent function of Lean environment matrix.

Table 3

Measurement scale of individual importance of lean attributes

\begin{tabular}{clc}
\hline S. No. & $\begin{array}{l}\text { Qualitative measure of Lean elements at sub- system level } \\
\text { impacting Lean Attributes }\end{array}$ & Value assigned at sub level \\
\hline 1 & Rare & 1 \\
2 & Very low & 2 \\
3 & Low & 3 \\
4 & Below average & 4 \\
5 & Average & 5 \\
6 & Above average & 6 \\
7 & High & 7 \\
8 & Very high & 8 \\
\hline
\end{tabular}

Step 4: Developing the digraphs for each sub factors based on the relative importance among different lean elements. 

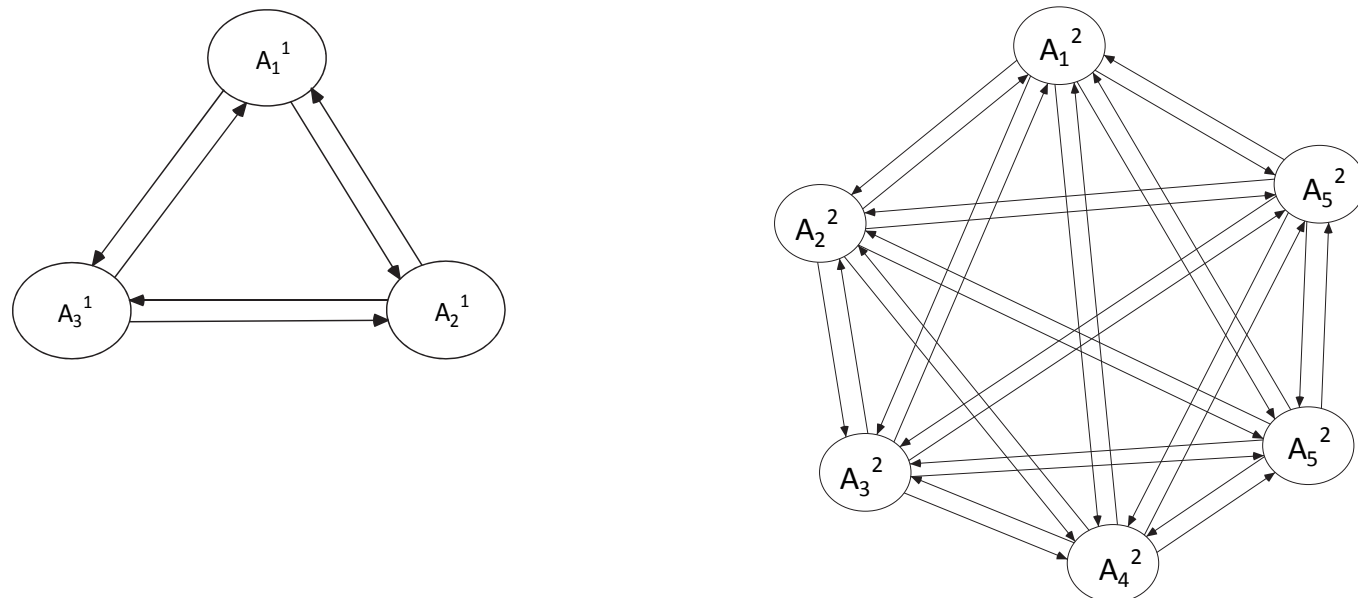

Fig. 4. Diagraph of Lean attributes - Supplier participation

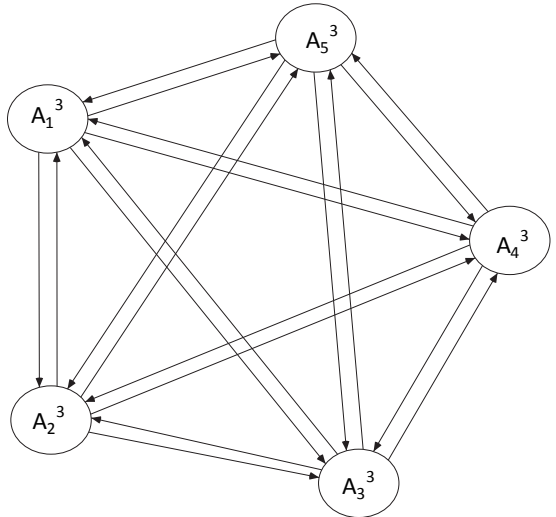

Fig. 5. Diagraph of Lean attributes Operational initiative

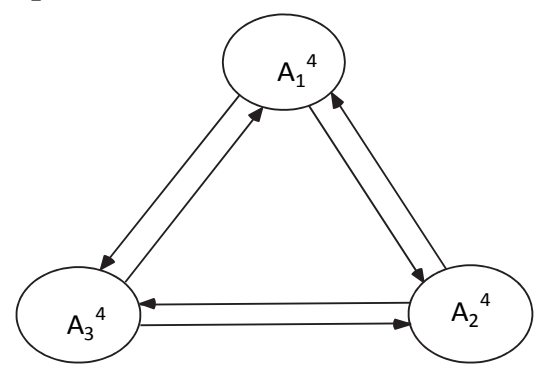

Fig. 6. Diagraph of Lean attributes Employee's involvement

Fig. 7. Diagraph of Lean attributes Customer participation

Step 5: Construction of the variable permanent matrix derived from the diagraphs.

Variable permanent matrix for Lean attributes 1: (Supplier participation)

$$
\left[\begin{array}{ccc}
\mathrm{A}_{1}{ }^{1} & 3 & 2 \\
3 & \mathrm{~A}_{2}{ }^{1} & 3 \\
2 & 3 & \mathrm{~A}_{3}{ }^{1}
\end{array}\right]
$$

Variable permanent matrix for Lean attributes 2: (Operational initiative)

$$
\left[\begin{array}{cccccc}
\mathrm{A}_{1}{ }^{2} & 2 & 2 & 4 & 4 & 3 \\
5 & \mathrm{~A}_{2}{ }^{2} & 2 & 4 & 4 & 3 \\
2 & 3 & \mathrm{~A}_{3}{ }^{2} & 2 & 3 & 2 \\
4 & 5 & 2 & \mathrm{~A}_{4}{ }^{2} & 3 & 4 \\
4 & 4 & 3 & 3 & \mathrm{~A}_{5}{ }^{2} & 4 \\
4 & 4 & 2 & 3 & 3 & \mathrm{~A}_{6}{ }^{2}
\end{array}\right]
$$


Variable permanent matrix for Lean attributes 3: (Employee's involvement)

$$
\left[\begin{array}{ccccc}
\mathrm{A}_{1}{ }^{3} & 3 & 2 & 3 & 2 \\
4 & \mathrm{~A}_{2}{ }^{3} & 3 & 4 & 3 \\
1 & 4 & \mathrm{~A}_{3}{ }^{3} & 3 & 3 \\
3 & 5 & 4 & \mathrm{~A}_{4}{ }^{3} & 4 \\
2 & 4 & 2 & 4 & \mathrm{~A}_{5}{ }^{3}
\end{array}\right]
$$

Variable permanent matrix for Lean attributes 4: (Customer participation)

$$
\left[\begin{array}{ccc}
\mathrm{A}_{1}{ }^{4} & 3 & 2 \\
3 & \mathrm{~A}_{2}{ }^{4} & 4 \\
3 & 3 & \mathrm{~A}_{3}{ }^{4}
\end{array}\right]
$$

The relative importance among the lean elements was quantified as per Table 3 . In the attribute level matrix, diagonal value for the elements was assigned as given below:

$$
\begin{aligned}
& A_{1}^{1}=7 ; A_{2}^{1}=7 ; A_{3}^{1}=8 ; \\
& A_{1}^{2}=6 ; A_{2}^{2}=7 ; A_{3}^{2}=6 ; A_{4}^{2}=7 ; A_{4}^{2}=8 ; A_{6}^{2}=7 ; \\
& A_{1}^{3}=8 ; A_{2}^{3}=6 ; A_{3}^{3}=7 ; A_{4}^{3}=6 ; A_{4}^{3}=8 ; \\
& A_{1}^{4}=8 ; A_{2}^{4}=7 ; A_{3}^{4}=8 ;
\end{aligned}
$$

Step 6. Quantitative importance for lean attributes for the organization was achieved through calculating permanent function values of $\left(\mathrm{A}_{1} \ldots \mathrm{A}_{4}\right)$ and $\left(\mathrm{a}_{\mathrm{ij}}\right)$ in the matrix.

The permanent function value of each attribute was computed. For example permanent function value of the first category matrix (1) was calculated as:

$$
\begin{aligned}
& a_{41} \times a_{32} \times a_{23} \times a_{14}+a_{31} \times a_{42} \times a_{23} \times a_{14}+a_{41} \times A_{2} \times A_{3} \times a_{14}+a_{21} \times a_{42} \times A_{3} \times a_{14}+a_{31} \times A_{2} \times a_{43} \times A_{14} \\
& +a_{21} \times a_{32} \times a_{43} \times a_{14}+a_{41} \times a_{32} \times a_{13} \times a_{24}+a_{31} \times a_{42} \times a_{13} \times a_{24}+a_{41} \times a_{12} \times A_{3} \times a_{24}+ \\
& A_{1} \times a_{42} \times A_{3} \times a_{24}+a_{31} \times a_{12} \times a_{43} \times a_{24}+A_{1} \times a_{32} \times a_{43} \times a_{24}+a_{41} \times A_{2} \times a_{13} \times a_{34}+a_{21} \times a_{42} \times a_{13} \times a_{34} \\
& +a_{41} \times a_{12} \times a_{23} \times a_{34}+A_{1} \times a_{42} \times a_{23} \times a_{34}+a_{21} \times a_{12} \times a_{43} \times a_{34}+A_{1} \times A_{2} \times a_{43} \times a_{34}+ \\
& a_{31} \times A_{2} \times a_{13} \times A_{4}+a_{21} \times a_{32} \times a_{13} \times A_{4}+a_{31} \times a_{12} \times a_{23} \times A_{4}+A_{1} \times a_{32} \times a_{23} \times A_{4}+a_{21} \times a_{12} \times A_{3} \times A_{4} \\
& +A_{1} \times A_{2} \times A_{3} \times A_{4}
\end{aligned}
$$

Permanent function value of the first category matrix (1) is given in Eq. (7). Similarly permanent function values of all categories were calculated and as shown below:

$\mathrm{A} 1=591, \mathrm{~A} 2=2387880, \mathrm{~A} 3=130352$ and $\mathrm{A} 4=712$.

Step 7: Lean environment is derived as per matrix no. 2. The values in this matrix for the diagonal elements are used from outcome of the sub-factor level matrices 3, 4,5and 6 . The permanent function of matrix no. 7 would be the index for lean environment of the organization. 


$\left[\begin{array}{cccc}591 & 2 & 2 & 0 \\ 4 & 2387880 & 5 & 4 \\ 3 & 5 & 130352 & 3 \\ 0 & 3 & 2 & 712\end{array}\right]$

$\mathrm{VPF}=1.30978^{*} 10^{17}$

Hence the LM index for the given company is $1.30978 * 10^{17}$

\section{Comparison and benchmarking}

For evaluating and comparing of lean environment between two different companies for example we have discussed a specific company in this paper, Say Company $\mathrm{X}$ and let there is another Company Y, In this case similarity and dissimilarity coefficient are assumed from 1 and 0 . Say if the company $\mathrm{X}$ and $\mathrm{Y}$ are similar from viewpoint of lean environment the similarity coefficient (Cs) is assumed 1 and the dissimilarity coefficient $(\mathrm{Cd})$.

$$
\mathrm{C}_{\mathrm{d}}=\left(\frac{1}{\mathrm{U}}\right) \sum i j \mu i j
$$

where, $\mathrm{U}=$ maximum of lean environment in the company

$$
\mu i=\text { Difference of lean environment between two companies. }
$$

Hence coefficient of similarity is $C_{s}=1-C_{d}$

For example we assume the permanent function value of company $\mathrm{Y}$ is $1.1 \times 10^{17}$. And value as of organization $\mathrm{X}$ in given example is calculated as $1.30978 \times 10^{17}$

Now using Eq. (9) we can calculate $C_{d}=0.763 \times 10^{-16}\left(0.20978 \times 10^{16}\right)=0.160$.

Hence, coefficient of similarity i.e. $\mathrm{C}_{\mathrm{s}}=1-0.160=0.84$ so the outcome of this example is that company $\mathrm{X}$ and company $\mathrm{Y}$ have higher similarity coefficient than coefficient of dissimilarity.

\section{Conclusion and discussion}

In this study the importance of various attributes of LM is evaluated. Four major parameters, Supplier participation, employee's involvement, operational initiatives and customer participation have been identified responsible for implementation of LM. Structured graph is drawn for these lean attributes and matrices are formed based on relative importance of these lean attributes using graph theoretic approach. Professionals were requested from academic and industries to quantify the importance among the different lean attributes. Diagram and matrix for different lean elements constituting lean enablers is based on their relative importance. All matrices are solved and valve for each lean attribute is calculated based on eqn.1, constructed and depicted in table below.

Table 4

Values for maximum, minimum and observed values of relative importance of lean attributes

\begin{tabular}{lcccc}
\hline Lean Attributes & Maximum & Minimum & Observed & Improvement opportunity \\
\hline Supplier participation & 963 & 59 & 591 & $41 \%$ \\
Operational initiatives & $4.89 \times 10^{6}$ & 366863 & $2.39 \times 10^{6}$ & $55 \%$ \\
Employee involvement & 237558 & 16438 & 130352 & $48 \%$ \\
Customer participation & 1962 & 458 & 712 & $83 \%$ \\
\hline
\end{tabular}


The observed value of lean attribute is the level of importance given to a particular lean attribute in lean environment of industry. The maximum and minimum value indicates the range within which it may vary. The maximum value is calculated by taking maximum value of diagonal elements and minimum value are calculated with considering minimum values of diagonal elements ranging from 9 $\max$ to $1 \mathrm{~min}$ as per table 3 . Actual measurement values can be obtained with the given method to know the importance given to different lean attributes. The Improvement opportunity shown in table for lean attributes is calculated as:

Available Improvement opportunity $=$

Maximum value - Observed value

Maximum value - Minimum value

Improvement opportunity means the percentage by which it can be further improved.

Graph theoretic approach is used to obtain numerical value for lean elements and attributes from the quantitative value of their importance. Permanent function equation was derived as $1.30978 \times 10^{17}$ for matrices and it can be additionally used for assessment of significance of lean attributes in a LM environment. Mathematical output in the form of numerical value is very helpful to the professionals to know the rank of different lean elements and attributes to understand strong and weak areas. Lean manufacturing index was calculated and was used to compare with an industry. The ranking for significance of the lean attributes was calculated via permanent value. Lean attribute operational initiatives were found to have a maximum value of $2.39 \times 10^{6}$ validating high importance of the operational initiatives lean attribute. This was followed by Employee involvement with a count of 237558, Customer participation with count equal to 1962 and Supplier participation with 963 counts, respectively. Lean elements like Supplier rating, TPM, 5S, Quality circles, customer feedback and online demand access are considered as significant elements of LM in industry (Kumar and Kumar, 2015). Industry can decide about action plan to take care of vital lean elements and attributes. This paper highlights the scope of improvement in supplier participation by $41 \%$, employee's involvement by $48 \%$, operational initiative $55 \%$ and customer participation to the tune of $83 \%$.

In this paper we distilled all lean elements into four lean attributes based on the domain of application and developed a bench-marking for measuring their relative importance in a lean manufacturing environment. This paper also presented a framework that reflects about the lean manufacturing more broadly by putting supplier and customer oriented activities together with internal activities and employee involvement. The lean environment measurement model presented in the paper is empirically validated and helpful for practitioners and researchers who are involved in carrying out survey research pertaining to lean manufacturing. This model may support the practitioners and researchers to evaluate and compare the lean environment among the manufacturing organizations. In addition, this paper provides an instrument for practicing managers to evaluate the status of lean manufacturing environment in their specific function.

\section{Acknowledgement}

The author would like to thank the anonymous referees for constructive comments on earlier version of this paper.

\section{References}

Ahuja, I. P. S., \& Khamba, J. S. (2008). An evaluation of TPM initiatives in Indian industry for enhanced manufacturing performance. International Journal of Quality \& Reliability Management, 25(2), 147-172.

Anand, G., \& Kodali, R. (2008). Selection of lean manufacturing systems using the PROMETHEE. Journal of modelling in management, 3(1), 40-70. 
Singh, B., Garg, S. K., \& Sharma, S. K. (2009). Lean can be a survival strategy during recessionary times. International journal of productivity and performance management, 58(8), 803-808.

Biswal, P. C. (2012). Discrete mathematics and graph theory. PHI Learning Pvt. Ltd.

Chowdary, B. V., \& George, D. (2011). Improvement of manufacturing operations at a pharmaceutical company: a lean manufacturing approach. Journal of Manufacturing Technology Management, 23(1), 56-75.

Dombrowski, U., Mielke, T., \& Engel, C. (2012). Knowledge management in lean production systems. Procedia CIRP, 3, 436-441.

Gross, J. L., \& Yellen, J. (2005). Graph theory and its applications. CRC press.

Grover, S., Agrawal, V. P., \& Khan, I. A. (2006). Role of human factors in TQM: a graph theoretic approach. Benchmarking: An International Journal, 13(4), 447-468.

Khadse, P. B., Sarode, A. D., \& Wasu, R. (2013). Lean manufacturing in Indian industries: A Review. International Journal of Latest Trends in Engineering and Technology, 3(1), 175-181.

Kumar, R., \& Kumar, V. (2012, October). Lean Manufacturing System: An overview. In Proceedings of the National Conference on Trends and Advances in Mechanical Engineering, YMCA. University of Science \& Technology, Faridabad, Haryana (pp. 742-747).

Kumar, R., \& Kumar, V. (2014). Barriers in implementation of lean manufacturing system in Indian industry: A survey. International Journal of Latest Trends in Engineering and Technology, 4(2), 243-251.

Kumar, R., \& Kumar, V. (2015). Lean manufacturing in Indian context: A survey. Management Science Letters, 5(4), 321-330.

Kumar, V. (2010). JIT based quality management: concepts and implications in Indian context. International Journal of Engineering Science and Technology, 2(1), 40-50.

Li, S., Rao, S. S., Ragu-Nathan, T. S., \& Ragu-Nathan, B. (2005). Development and validation of a measurement instrument for studying supply chain management practices. Journal of Operations Management, 23(6), 618-641.

Mishra, O. P., Kumar, V., \& Garg, D. (2013). Evaluating Distribution Process of a Supply Chain in Just-in-Time Environment Using Application of Graph Theory. Management, 8(4), 018-025.

Mishra, O., \& Garg, D. (2013). JIT supply chain; an investigation through general system theory. Management Science Letters, 3(3), 743-752.

Nordin, N., Deros, B. M., \& Wahab, D. A. (2010). A survey on lean manufacturing implementation in Malaysian automotive industry. International Journal of Innovation, Management and Technology, 1(4), 374-380.

Pemmaraju, S., \& Skiena, S. (2003). Computational Discrete Mathematics: Combinatorics and Graph Theory with Mathematica ${ }^{\circledR}$. Cambridge university press.

Pepper, M. P. J., \& Spedding, T. A. (2010). The evolution of lean Six Sigma. International Journal of Quality \& Reliability Management, 27(2), 138-155.

Rao, R. V., \& Gandhi, O. P. (2002). Failure cause analysis of machine tools using digraph and matrix methods. International Journal of Machine Tools and Manufacture, 42(4), 521-528.

Shah, R., \& Ward, P. T. (2003). Lean manufacturing: context, practice bundles, and performance. Journal of operations management, 21(2), 129-149.

Shah, R., \& Ward, P. T. (2007). Defining and developing measures of lean production. Journal of operations management, 25(4), 785-805.

Taj, S., \& Morosan, C. (2011). The impact of lean operations on the Chinese manufacturing performance. Journal of manufacturing technology management, 22(2), 223-240.

Silva, S. K. P. N. (2012). Applicability of value stream mapping (VSM) in the apparel industry in Sri Lanka. International Journal of Lean Thinking, 3(1), 36-41.

Spear, S., \& Bowen, H. K. (1999). Decoding the DNA of the Toyota production system. Harvard Business Review, 77, 96-108.

Upadhye, N., Deshmukh, S. G., \& Garg, S. (2010). Lean manufacturing system for medium size manufacturing enterprises: an Indian case. International Journal of Management Science and Engineering Management, 5(5), 362-375. 
160

Womack, J. P., Jones, D. T., \& Roos, D. (1990). The Machine that Changed the World (HarperPerennial, New York, NY). 